\title{
Commentary: Splenectomy during thoracoabdominal aortic surgery: Lessons learned
}

\author{
Nicholas T. Kouchoukos, MD
}

\author{
From the Division of Cardiovascular and Thoracic Surgery, Missouri Baptist Medical Center, BJC Healthcare, St \\ Louis, Mo. \\ Disclosures: Author has nothing to disclose with regard to commercial support. \\ Received for publication July 19, 2019; accepted for publication July 22, 2019. \\ Address for reprints: Nicholas T. Kouchoukos, MD, Division of Cardiovascular and Thoracic Surgery, Missouri \\ Baptist Medical Center, 3023 N Ballas Rd, Suite 150D, St Louis, MO 631331 (E-mail: ntkouch@aol.com). \\ J Thorac Cardiovasc Surg 2020;160:653 \\ $0022-5223 / \$ 36.00$ \\ Copyright (C) 2019 by The American Association for Thoracic Surgery \\ https://doi.org/10.1016/j.jtcvs.2019.07.066
}

Incidental (iatrogenic) splenectomy (IS) is a well-recognized complication associated with major abdominal surgical procedures. Important risk factors for its occurrence include previous abdominal operations, obesity, left upper quadrant incisions, and the retroperitoneal approach to abdominal pathology, particularly with visceral medial rotation. ${ }^{1,2}$ Early complications associated with IS include increased rates of bleeding, transfusion of blood products, infection, and mortality. ${ }^{1,3,4}$ Little information is available on the frequency and implications of IS among patients undergoing thoracoabdominal aortic aneurysm (TAAA) repair.

Chaterjee and colleagues ${ }^{5}$ report the outcomes of patients with IS associated with repair of TAAA in a series of 1046 patients treated over a 10-year interval. IS occurred in $13 \%$ of patients, was associated with a significantly higher early mortality rate (16\% vs $8 \%$ ), and was an independent predictor of early mortality but did not increase the risk of late mortality. IS patients required transfusion of more blood products. In a propensity analysis of 132 matched cohorts, the IS patients had significantly higher rates of sepsis, respiratory failure, tracheostomy, gastrointestinal complications, and a history of more reoperations and open distal aortic repair. The authors did not provide information about the relative frequency with which an intraperitoneal or extraperitoneal approach to repair was used to determine whether or not there was a difference in the prevalence of IS, or about the number of patients in whom repair of splenic injuries was successfully performed. They also did not analyze overall survival incorporating the early deaths, which might have yielded a different outcome. Putting these limitations aside, they have provided an excellent analysis of the risks associated with splenectomy during TAAA repair.

What are the lessons to be learned from this extensive experience?

1. Given the characteristics of patients presenting for TAAA repair, IS is likely an unavoidable complication, especially in patients with previous TAAA repair or distal aortic surgery. However, every effort should be made to minimize the risk of splenic injury, particularly

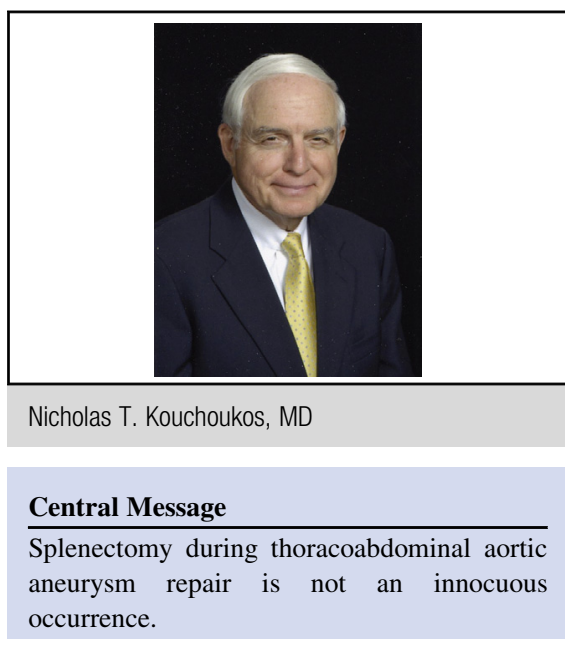

See Article page 641.

the avoidance of excessive tension on the spleen and its pedicle from manual or mechanical retraction.

2. Bleeding from missed or mismanaged splenic injuries carries a high risk of early death. Prompt reoperation should be carried out if bleeding from the spleen is suspected.

3. Given the higher rates of sepsis and mortality due to sepsis in IS patients, all such patients should receive triple immunization immediately after splenectomy.

4. Surviving patients with IS should be counseled regarding their increased risk of infection and possibly of thromboembolic complications, and should seek immediate medical attention when either of these complications occurs.

5. Repair of minor splenic injuries should be attempted whenever possible.

\section{References}

1. Cassar K, Munro A. Iatrogenic splenic injury. J R Coll Surg Edinb. 2002;47: 731-41.

2. Reilly LM, Ramos TK, Murray SP, Cheng SW, Stoney RJ. Optimal exposure of the proximal aorta: a critical appraisal of transabdominal medial visceral rotation. $J$ Vasc Surg. 1994;19:375-89.

3. Eaton MA, Valentine J, Jackson MR, Modrall G, Clagett P. Incidental splenic injury during abdominal vascular surgery: a case-controlled analysis. J Am Coll Surg. 2000;190:58-64

4. Barmparas G, Lamb AW, Lee D, Nguyen B, Eng J, Bloom MB, et al. Postoperative infection risk after splenectomy: a prospective cohort study. Int $J$ Surg. 2015;10-4.

5. Chatterjee S, LeMaire SA, Green SY, Price MD, Hiruni S, Amarasekara HS, et al Is incidental splenectomy during thoracoabdominal aortic aneurysm repair associated with reduced survival? J Thorac Cardiovasc Surg. 2020;160:641-52.e2. 